\title{
Situation of Lung Cancer among The Population of Mongolia
}

\author{
Odontuya Davaasuren* \\ President of Mongolian Palliative Care Society, Mongolia
}

Received: 㘹: December 23, 2018; Published: 証: January 09, 2019

*Corresponding author: Odontuya Davaasuren, president of Mongolian Palliative Care Society, Mongolia

\section{Abstract}

Background: Mongolians have World's worst air. Power plants in winter time work nonstop because of severe cold winter time in Mongolia. Smoke from coal fires shrouds the shantytowns of the capital, Ulaanbaatar, in a brown fog in winter time. Levels of air pollution in Mongolia 80 times more than recommended safety level set by the WHO.

Method: Systematic reviews and observational studies on lung cancer in Mongolia have taken place over the past 10 years.

Results: Critical level of air pollution and highest incidence of respiratory diseases make Mongolian population prone and risky to lung cancer. Since 2008 till 2017 the incidence of respiratory diseases increased from 972.9 till 1647.4 per 10000 population. Mortality rate from cancer increased from 11.80 in 2008 till 13.03 in 2017. Lung cancer is a $3^{\text {rd }}$ cancer within hall population of Mongolia, and 3rd cancer within man population and 10th cancer within women population in Mongolia. In 2007, level of the lung cancer in Mongolia was 9.9 per 100.000 population, in 2017 the incidence rate of lung cancer became 14. In 2017 93.8\% of lung cancer diagnosed in incurable stage III, IV and just $6.2 \%$ of lung cancer diagnosed in the stage I, II. 64\% (280) of patients within 435 new registered lung cancer patients in Mongolia in 2017 received palliative treatment and just 36\% of lung cancer patients received different combination of anticancer treatment

Conclusion: Available data indicate that danger air pollution, increased incidence of respiratory diseases, increased risk of lung cancer in Mongolia. There is a very important to implement real national program against air pollution. In Mongolia, approximately $93.8 \%$ of the lung cancer patients were diagnosed at the late stage (III and IY), which requires the implementation of early detection and good treatment of lung cancer program.

\section{Background}
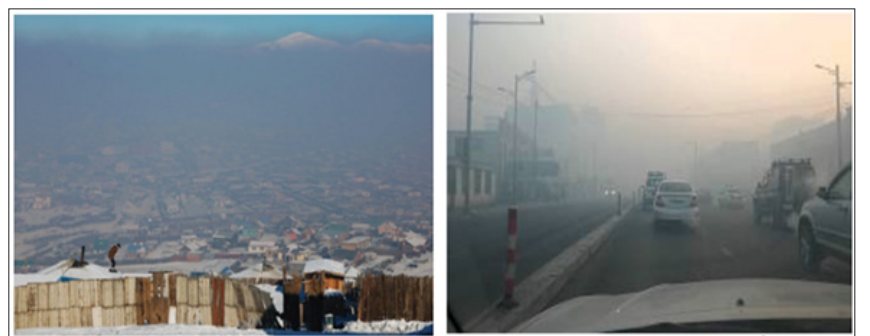

Figure 1: Smoke from coal fires shrouds the shantytowns of the capital, Ulaanbaatar, in a brown fog in winter time.

Territory of Mongolia is 1,565 million $\mathrm{km}^{2}$. Population of Mongolia is 3 million 177.9 thousand. $67.6 \%$ of population lives in cities and $32.4 \%$ resides in rural areas. 1463.0 thousand people or $46.0 \%$ of the population resides in Ulaanbaatar. The middle life expectancy at birth in 2017 was 69.9. Female life expectancy is 75.4 years and male life expectancy is 65.9 years. $30.5 \%$ of the population is children under 15 years, $65.7 \%$ aged 15-64 years, and $3.9 \%$ is over $65[1,11]$. World's worst air have Mongolians seeing Red, Planning Action. Power plants in winter time work nonstop because of severe cold winter time in Mongolia. Smoke from coal fires shrouds the shantytowns of the capital, Ulaanbaatar, in a brown fog in winter time (Figure 1). Levels of air pollution in Mongolia 80 times more than recommended safety level set by the WHO. The daily average levels of particulate matter in the air settled at 1,071 micrograms in December [2-4].

The World Health Organization recommends exposure of no more than 25 micrograms over 24 hours. According to the World Bank, if the air pollution in Ulaanbaatar was reduced by 50 per cent, the country would save $\$ 19$ million to $\$ 38$ million in healthcare costs. However, we still don't think the government prioritizes this pressing issue as much as it should [2-4]. Almost 6 million people were killed by tobacco use in the World per year. Consumption of 
cigarettes per person per year in Mongolia is $500-1000.48 .2 \%$ of men, $5.9 \%$ of women, $5.4 \%$ of children under 15 currently smoking tobacco products in Mongolia [5,6] (Figure 2). Government of Mongolia pledges to intensify fight against air pollution and provide some activities:

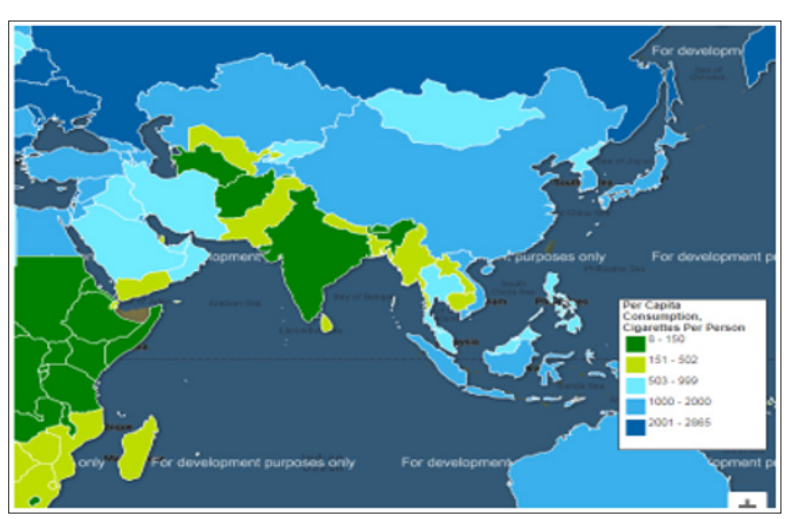

Figure 2: Per capita consumption of cigarettes per person.

a) Discounted night-time electricity for households in ger areas with a budget of MNT 9 billion which continues this year.

b) Set up a National Committee on Air Pollution Reduction

c) On December 13, 2017, the Committee decided to intensify the removal of steam boilers, increase energy sources, introduce technological innovation in governmentrun buildings and facilities, increase the number of air quality monitoring stations, provide processed fuel to target groups and run a campaign on reducing heat loss.

d) A fund of MNT17 billion was projected in the 2018 State Budget to reduce air pollution. e) Government promised installation of air purifiers in all schools and kindergartens in 2018 by MNT 4 billion.

f) Considering the sharp increase of respiratory diseases children, in winter caused by air pollution, decided to issue up to 5-days of paid leave to parents looking after their ill children.

But air quality in the capital city hasn't noticeably improved despite spending MNT147 billion from the budget and USD 60 million in foreign investment in 2008-2016 [7].

\section{Methods}

Systematic reviews and observational studies on lung cancer in Mongolia have taken place over the past 10 years.

\section{Results}

Very poor air condition in Mongolia, especially in winter time, high smoking habits within men population, incidence of respiratory diseases in Mongolia is highest, and it is a one of leading cause of morbidity in Mongolia. Critical level of air pollution and highest incidence of respiratory diseases make Mongolian population prone and risky to lung cancer. Since 2008 till 2017 the incidence of respiratory diseases increased from 972.9 till 1647.4 per 10000 population (Figure 3). 5 leading causes of mortality in Mongolia are cardiovascular diseases, cancer, injuring and poisoning, respiratory diseases [14]. Mongolian government implemented program for prevention and control of noncommunicable diseases, and as the result the mortality rate from the diseases of the circulatory system decreased from 20.54 in 2008 till 17.45 in 2017. But mortality rate from cancer increased from 11.80 in 2008 till 13.03 in 2017 [14]. 6073 new cancer cases registered in Mongolia in 2017, 63.8\% of them registered in rural area, 36.3\% -in capital Ulaanbaatar. Within new registered cancer cases 50.7\% were men, $49.3 \%$ were women [14] (Figure 4) and (Table 1).

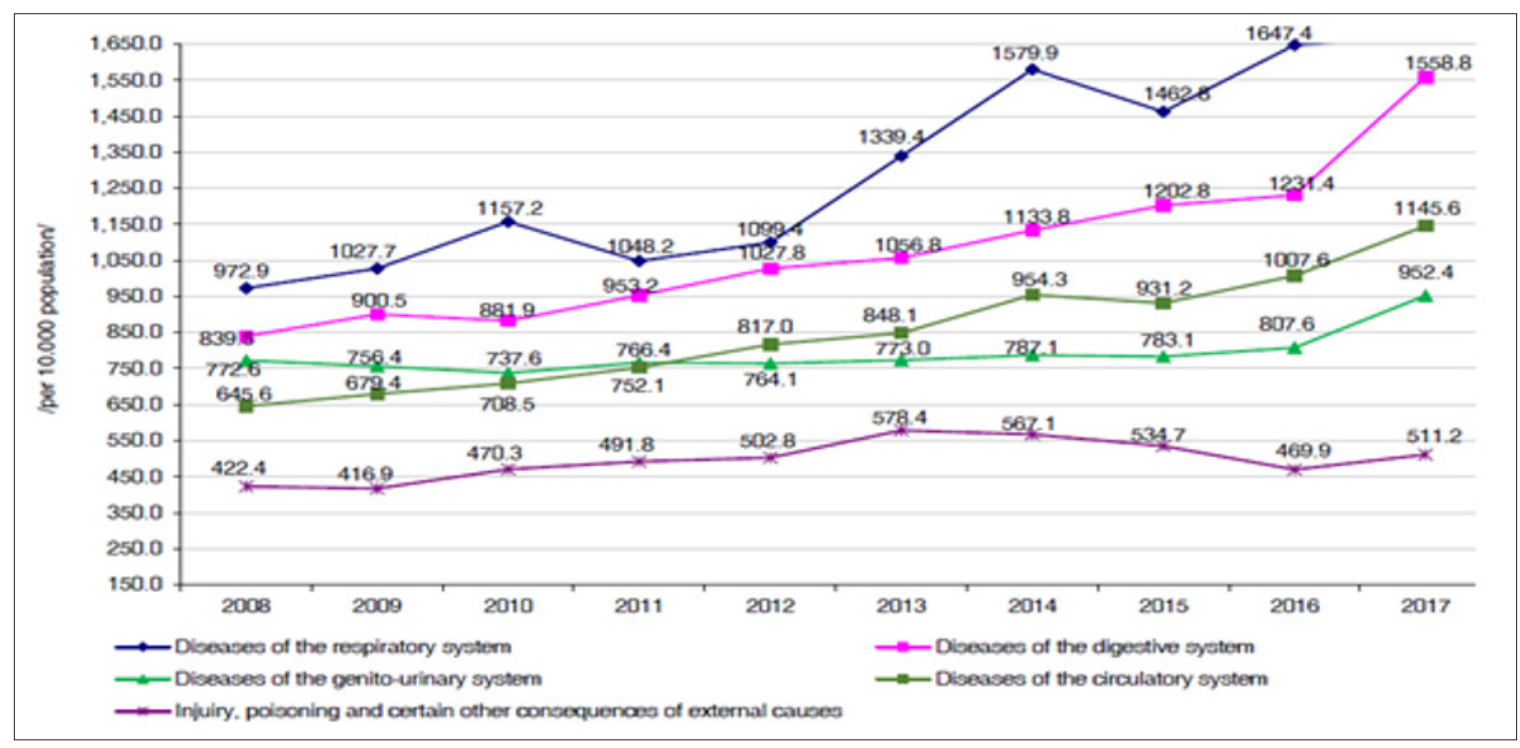

Figure 3: Five leading causes of morbidity in Mongolia per 10000 population, 2008-2017. 
Table 1: Common carcinoma in Mongolia, by sex, 2017.

\begin{tabular}{|c|c|c|c|c|c|c|}
\hline No & Total & $\%$ & Male & $\%$ & Female & $\%$ \\
\hline 1. & Liver & 38.1 & Liver & 40.4 & Liver & 35.7 \\
\hline 2. & Stomach & 14.6 & Stomach & 18.7 & Cervical & 11.9 \\
\hline 3. & Lung & 7.2 & Lung & 11.6 & Stomach & 10.5 \\
\hline 4. & Cervical & 5.9 & Esophagus & 6.0 & Breast & 8.2 \\
\hline 5. & Esophagus & 5.7 & Colon, rectum & 3.4 & Esophagus & 5.3 \\
\hline 6. & Breast & 4.1 & Urology, nephrology & 2.3 & Colon, rectum & 4.5 \\
\hline 7. & Colon and rectum & 4.0 & Pancreas & 2.0 & Ovary & 3.0 \\
\hline 8. & Urology, nephrology & 2.7 & Lymphoid leukemia & 1.9 & $\begin{array}{l}\text { Urology, } \\
\text { nephrology }\end{array}$ & 3.0 \\
\hline 9. & Pancreas & 2.3 & Brain & 1.4 & Pancreas & 2.6 \\
\hline 10. & Ovary & 1.5 & Pharynx & 1.2 & Lungs & 2.6 \\
\hline
\end{tabular}

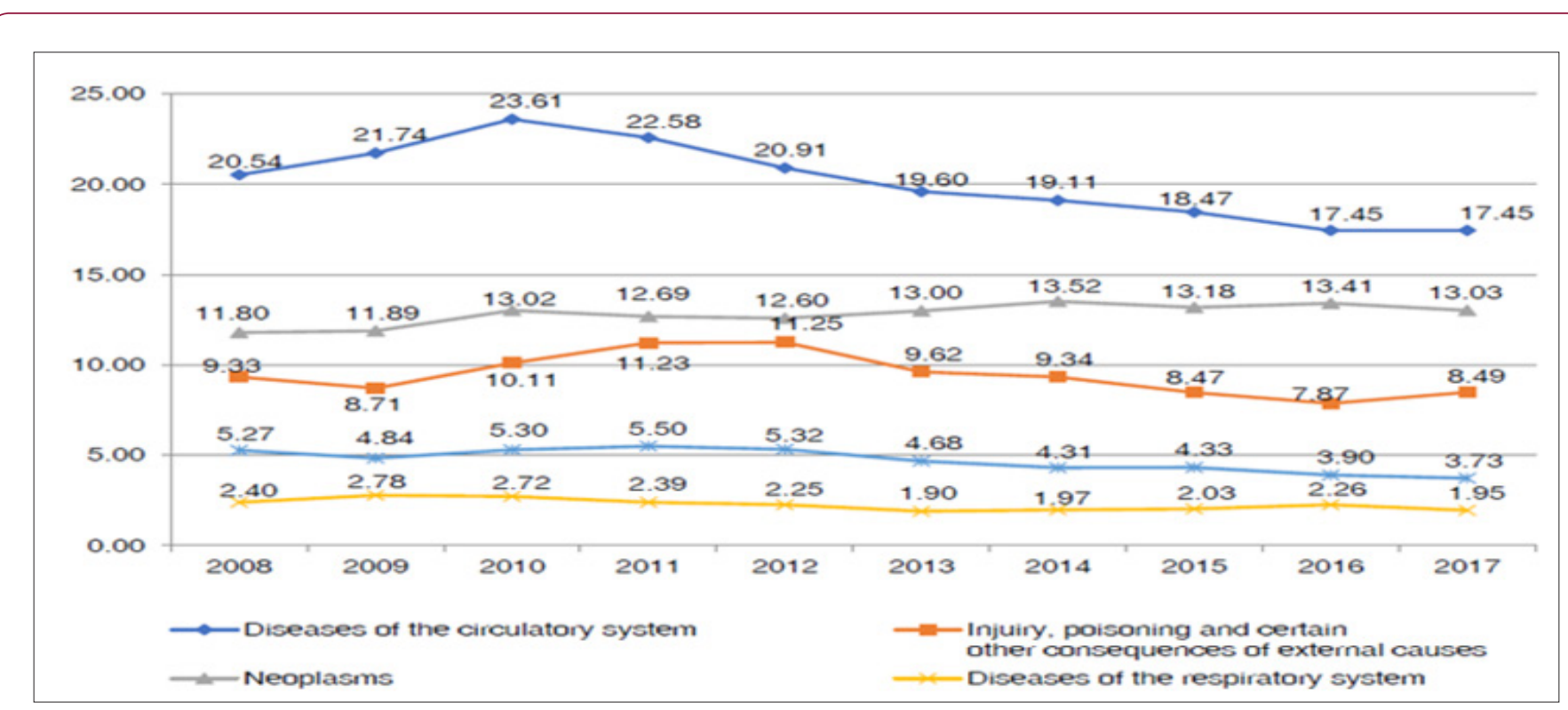

Figure 4: Five leading causes of mortality in Mongolia per 10000 population, 2008-2017.

Liver, stomach, lung, cervical and esophageal cancers are five leading cancers in Mongolia. In 2017, lung cancer is a $3^{\text {rd }}$ cancer within hall population of Mongolia, and $3^{\text {rd }}$ cancer within man population and 10th cancer within women population in Mongolia. In 2017, a total of 4004 cancer deaths (2262 cases in males and 1742 cases in females) were reported in Mongolia, which accounted for $25.4 \%$ of all deaths in the country. $14 \%$ of cancer death within men, $3.8 \%$ of cancer death within women caused by lung cancer [14] (Table 2). In 2007, level of the lung cancer in Mongolia was 9.9 per 100.000 population, in 2017 the incidence rate of lung cancer became 14 (Figure 5). So, it increased by 4.1 [8-14]. Agestandardized incidence rate per 100.000 population was the lowest in age group 35-39 (1.2 percent), followed by age groups 60-64 with rate 16.7 percent (Figure 6). The highest rate 18.2 percent in age group more than 75years [8-16] (Table 3). $21.7 \%$ of total cancer diagnosed in the early or curable stage of disease, and $78.3 \%$ of cancer diagnosed in the late or incurable stage of cancer. $93.8 \%$ of lung cancer diagnosed in incurable stage III, IV and just $6.2 \%$ of lung cancer diagnosed in the stage I, II, (Figure 7). 
Table 2: Number of deaths because of common cancer in Mongolia in 2017.

\begin{tabular}{|c|c|c|c|c|c|c|}
\hline No & Male & Number & Percent & Female & Number & Percent \\
\hline 1. & Liver & 920 & 40.7 & Liver & 694 & 39.8 \\
\hline 2. & Stomach & 402 & 17.8 & Stomach & 219 & 12.6 \\
\hline 3. & Lung & 316 & 14.0 & Cervical & 127 & 7.3 \\
\hline 4. & Esophagus & 155 & 6.9 & Esophagus & 120 & 6.9 \\
\hline 5. & Colon, rectum & 68 & 3.0 & Colon, rectum & 89 & 5.1 \\
\hline 6. & Pancreas & 50 & 2.7 & Breast & 75 & 4.3 \\
\hline 7. & Lip, oral cavity, pharynx & 30 & 1.3 & Pancreas & 69 & 4.0 \\
\hline 8. & Brain & 30 & 1.3 & Lung, bronchi & 66 & 3.8 \\
\hline 9. & Lymphoid, leukemia & 30 & 1.3 & Ovary & 55 & 3.2 \\
\hline 10. & Urology, nephrology & 28 & 1.2 & Brain & 32 & 1.8 \\
\hline & Total & 2262 & & & 1742 & \\
\hline
\end{tabular}

Table 3: The percentage of new cases of cancer and stages at time of diagnosis in Mongolia (TNM classification, 2017).

\begin{tabular}{|c|c|c|c|c|c|c|}
\hline No & Location of cancer & Ca insitu & I stage & II stage & III stage & IV stage \\
\hline 1. & Cervical & 21.1 & 8.7 & 18.3 & 42.4 & 9.6 \\
\hline 2. & Urology, nephrology & 0.4 & 4.5 & 26.8 & 52.4 & 15.9 \\
\hline 3. & Ovary & 0.0 & 8.8 & 23.1 & 40.7 & 27.5 \\
\hline 4. & Pancreas & 0.0 & 0.0 & 9.9 & 33.3 & 56.7 \\
\hline 5. & Esophagus & 0.6 & 1.5 & 5.8 & 63.1 & 29.1 \\
\hline 6. & Breast & 0.4 & 4.5 & 26.8 & 52.4 & 15.9 \\
\hline 7. & Lung & 0.0 & 0.9 & 5.3 & 53.6 & 40.2 \\
\hline 8. & Stomach & 1.0 & 3.1 & 10.3 & 43.9 & 41.6 \\
\hline 9. & Liver & 0.3 & 3.7 & 16.4 & 43.7 & 35.8 \\
\hline \multirow[t]{2}{*}{10.} & Colon, rectum & 1.6 & 1.6 & 13.7 & 40.8 & 42.3 \\
\hline & Total & 1.9 & 4.9 & 14.9 & 44.6 & 33.6 \\
\hline
\end{tabular}

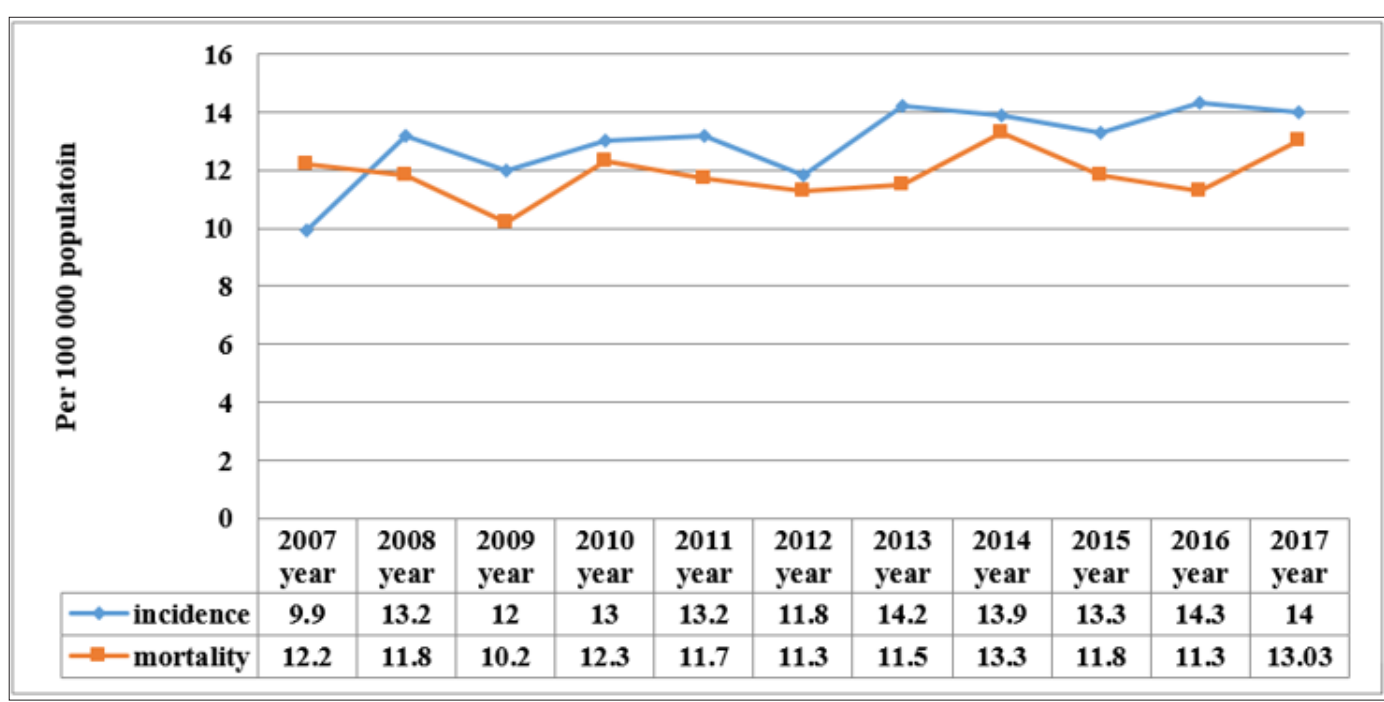

Figure 5: Incidence and mortality rate of lung cancer in Mongolia, 2007-2017. 


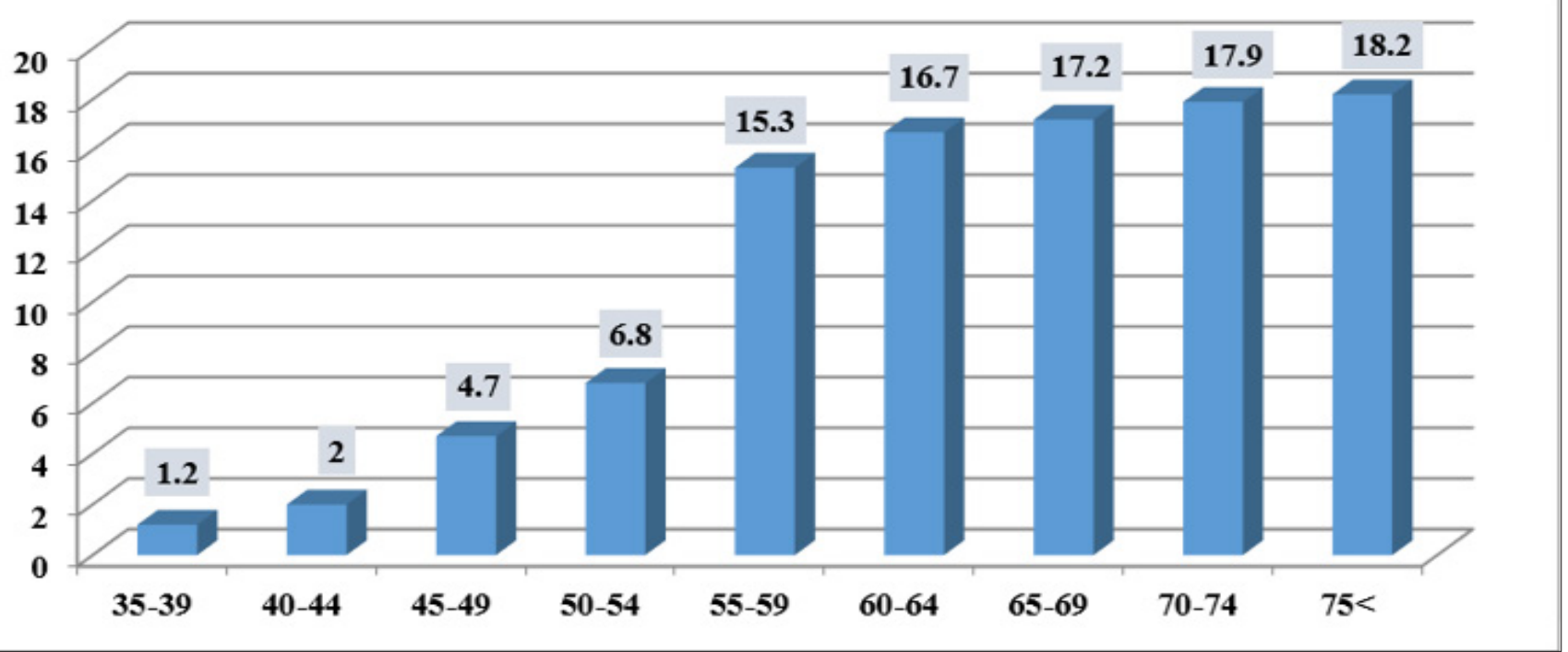

Figure 6: Age-standardized incidence rate of lung cancer per 100.000 population.

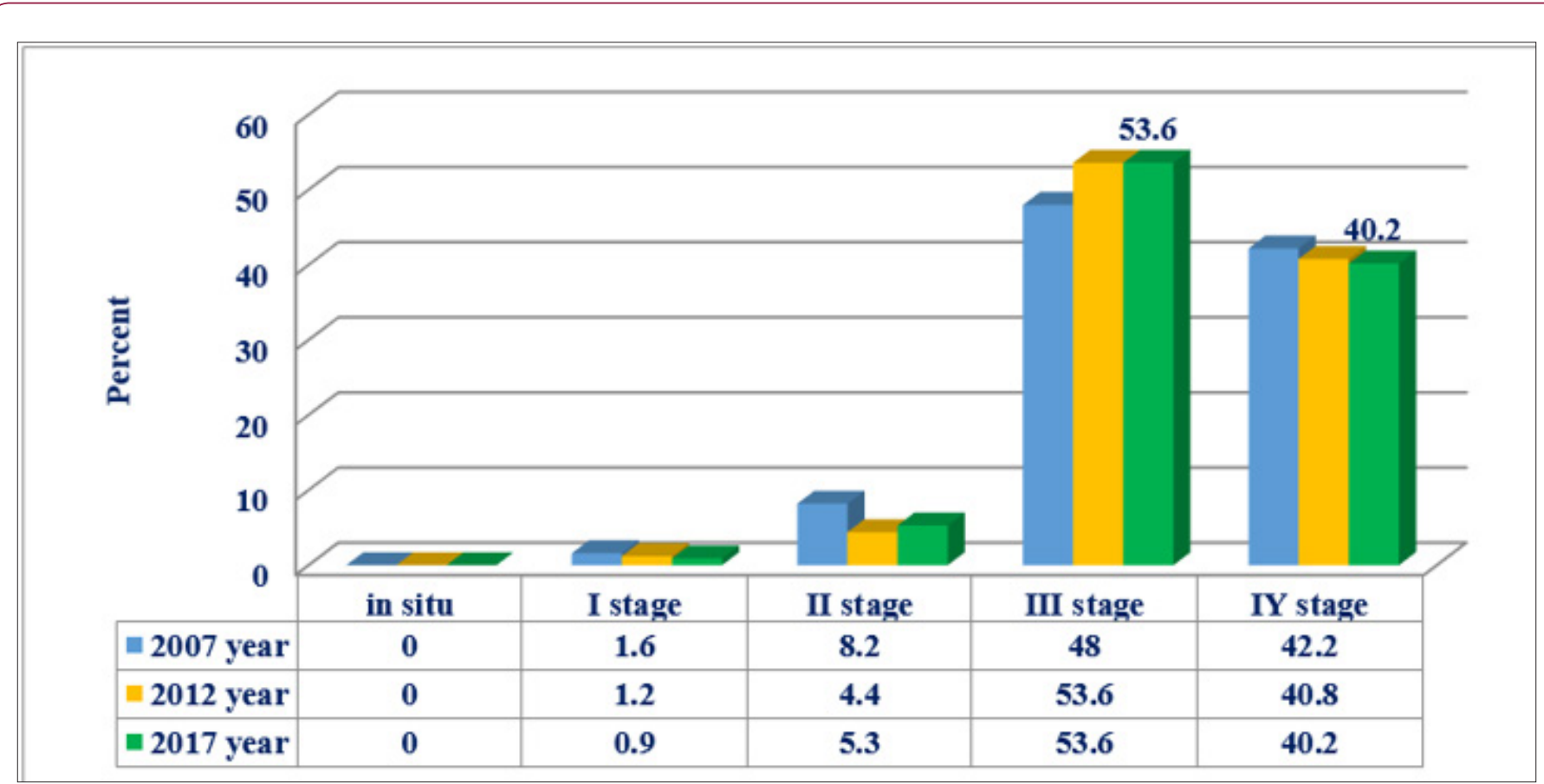

Figure 7: Stages of lung cancer diagnosis in Mongolia, 2007-2017.

A comparison of results from surveys for past 10 years shows that, diagnosis of Lung cancer had no tendency to early detection and more than $93 \%$ of lung cancer diagnosed in the late stage of disease [8-16]. 492 lung cancer patients monitored in the beginning of 2017, 435 patients newly registered in 2017 (Figure 8), totally monitored 927 lung cancer patients in Mongolia (Figure 9 \&10). But 382 patients died during 2017, 38 leaved monitoring, and in the end of 2017 just 507 patients with lung cancer were under the medical workers monitoring [18]. Diagnosis of lung cancer was approved in 175 patients by CT, 27 patients by Rey, 9 patients by bronchoscopy, 70 patients by biopsy from primary tumor, 50- by biopsy from metastasis, 39- by cytology, 26- by clinical signs, 42by Death certificate [18]. 64\% or 280 patients within 435 new registered Lung Cancer patients in Mongolia in 2017 received palliative treatment and just 36\%of lung cancer patients received different combination of anticancer treatment [18]. 


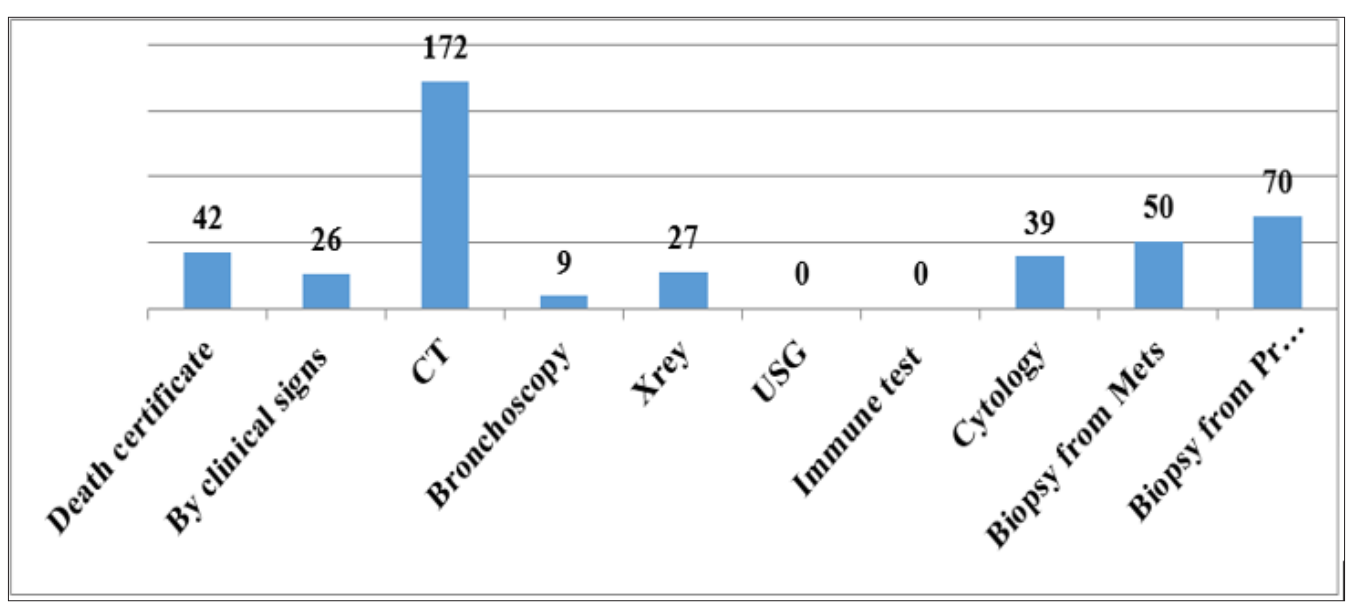

Figure 8: Methods of diagnosis lung cancer within 435 new registered lung cancer patients in Mongolia, 2017.

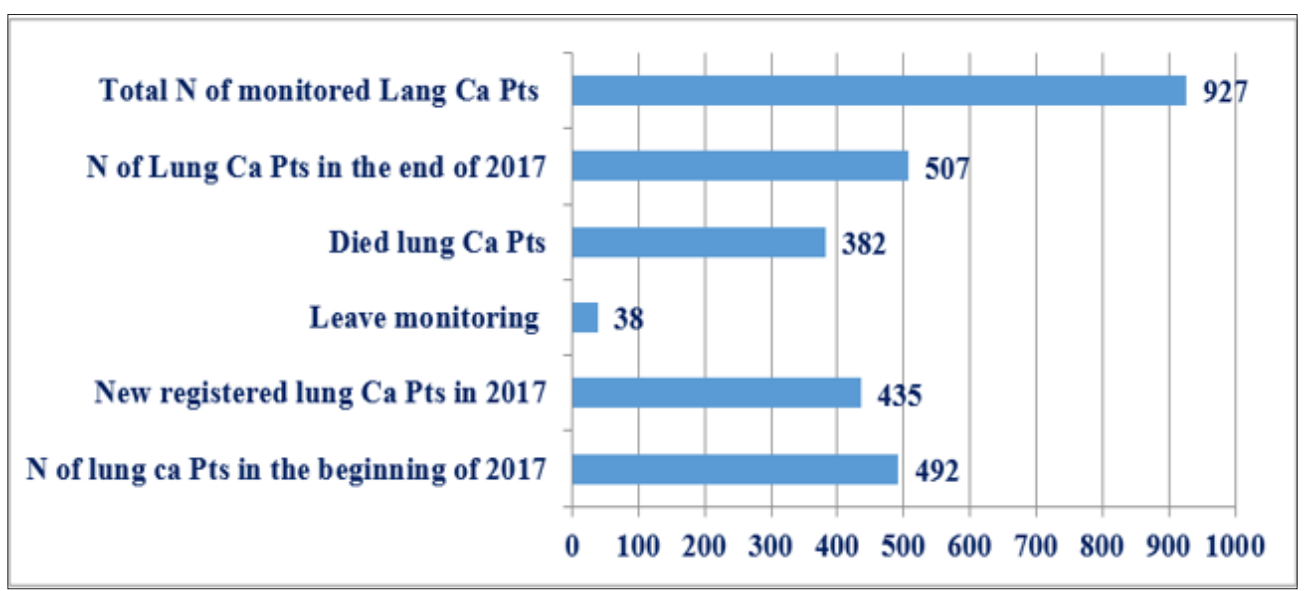

Figure 9: Number of lung cancer patients, who monitored by oncologists in 2017 in Mongolia.

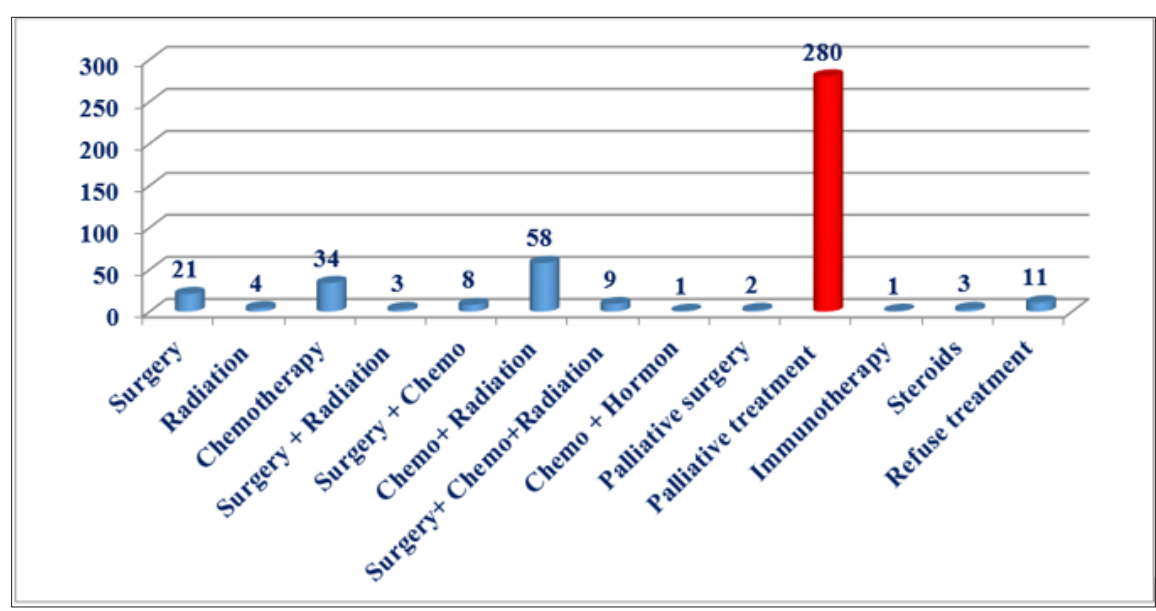

Figure 10: Methods of treatment lung cancer patients in Mongolia in 2017.

\section{Conclusion}

Available data indicate that danger air pollution, increased incidence of respiratory diseases, increased risk of lung cancer in
Mongolia. There is a very important to implement real national program against air pollution. In Mongolia, approximately $93.8 \%$ of the lung cancer patients were diagnosed at the late stage (III and 
IY), which requires the implementation of early detection program and development of comprehensive palliative care program. In Mongolia we need implementation of modern early detection and treatment method of lung cancer by cooperation with countries with advanced treatment and educate oncologists - doctors.

\section{References}

1. (2017) Health Indicators Mongolia.

2. Mongolian air pollution causing health crisis: UNICEF.

3. Mongolia's air pollution crisis - UNICEF

4. Mongolia's deadly air pollution chokes the 'Land of Eternal Blue Sky'.

5. Demaio AR, Nehme J, Otgontuya D, Meyrowitsch DW, Enkhtuya P (2014) Tobacco smoking in Mongolia: findings of a national knowledge, attitudes and practices study. BMC Public Health 14: 213.

6. Tobacco atlas: country by country.

ISSN: 2574-1241

DOI: 10.26717/BJSTR.2019.12.002322

Odontuya Davaasuren. Biomed J Sci \& Tech Res

(c) (P) This work is licensed under Creative

Submission Link: https://biomedres.us/submit-manuscript.php
7. Government pledges to intensify fight against air pollution.

8. (2007) Health Indicators, Mongolia.

9. (2008) Health Indicators, Mongolia.

10. (2009) Health Indicators, Mongolia.

11. (2010) Health Indicators, Mongolia.

12. (2011) Health Indicators, Mongolia.

13. (2012) Health Indicators, Mongolia.

14. (2014) Health Indicators, Mongolia.

15. (2015) Health Indicators, Mongolia.

16. (2016) Health Indicators, Mongolia.

17. (2017) Life Expectancy by Country.

18. 2017year Health statistics.

19. National cancer control program 2007-2017, Mongolia pp. 122. 